\title{
Human epidermal growth factor receptor 2 amplification as a biomarker for treatment in patients with lymph node-metastatic penoscrotal extramammary Paget's disease
}

\author{
XIAOLIN LU ${ }^{1,2^{*}}$, PEIPEI ZHANG ${ }^{3 *}$, YAO ZHU ${ }^{1,2}$ and DINGWEI YE ${ }^{1,2}$ \\ ${ }^{1}$ Department of Urology, Fudan University Shanghai Cancer Center; ${ }^{2}$ Department of Oncology, \\ Shanghai Medical College, Fudan University, Shanghai 200032; ${ }^{3}$ Department of Pathology, Rui Jin Hospital, \\ Shanghai Jiao Tong University School of Medicine, Shanghai 200025, P.R. China
}

Received April 18, 2018; Accepted December 5, 2018

DOI: $10.3892 / \mathrm{ol} .2019 .9930$

\begin{abstract}
The role of human epidermal growth factor receptor 2 (HER2) amplification as a biomarker for treatment in patients with lymph node (LN)-metastatic penoscrotal extramammary Paget's disease (EMPD) was investigated in the present study. A total of 11 male patients with LN-metastatic penoscrotal EMPD were retrospectively reviewed. Positron emission tomography/computed tomography (PET/CT) was conducted prior to surgery. Immunohistochemistry and fluorescence in situ hybridization were used to evaluate HER2 gene amplification in LN samples. Sanger sequencing was used to investigate HER2 mutations. A literature review of the prevalence of HER2 amplification in EMPD and the efficacy of HER2-targeted therapy was also undertaken. PET/CT is effective in detecting metastatic sites. The sensitivity and specificity of PET/CT was 90.9 and $100.0 \%$ for inguinal LNs, and 85.7 and $80.0 \%$ for pelvic LNs, respectively. The median time from $\mathrm{LN}$ dissection to disease progression was $15.9 \pm 1.5$ months. Of the 11 patients, 3 (27.3\%) indicated HER2 amplification. Patients with HER2 amplification showed shorter median times from disease discovery to LN metastasis (HER2 amplification vs HER 2 non-amplification; 15.6 vs. 10.0 months; $\mathrm{P}=0.50$ ) and from LN dissection to disease progression (HER2 amplification vs. HER2 non-amplification, 16.2 vs. 13.6 months; $\mathrm{P}=0.11$ ). However, the aforementioned observations were not
\end{abstract}

Correspondence to: Dr Yao Zhu or Professor Dingwei Ye, Department of Urology, Fudan University Shanghai Cancer Center, 270 Dongan Road, Shanghai 200032, P.R. China

E-mail: mailzhuyao@163.com

E-mail: dwyeli@163.com

*Contributed equally

Key words: penoscrotal extramammary Paget's disease, human epidermal growth factor receptor 2, positron emission tomography/computed tomography, surgery, targeted therapy indicated to be statistically significant. No HER 2 mutations were identified. Trastuzumab, a HER2-targeted monoclonal antibody, was administered to 2 of the patients with HER2 amplification. A literature review of the prevalence of HER2 amplification in EMPD and the efficacy of HER2-targeted therapy showed similar results. Altogether, 485 cases of EMPD were reported, 35 of which had metastases. The results in the present study suggest that PET/CT should be used on all metastatic EMPD patients. EMPD may be effectively treated with trastuzumab. The present study and case reports from the literature provide evidence for the benefit of testing for HER2 amplification in this rare disease and highlight the requirement for a multicenter clinical trial to assess the impact of trastuzumab therapy in treating this disease.

\section{Introduction}

Extramammary Paget's disease (EMPD) is a malignancy mostly identified on gland-bearing skin, including the scrotum, vulva and anus. No specific incidence rate has been recorded since the disease is quite rare (1).

Previous studies have shown that EMPD constitutes only $6.5 \%$ of all cases of Paget's disease (2). As the clinical manifestation of EMPD is similar to that of eczema or dermatitis, pathological examination may be delayed. Primary EMPD has a good prognosis, but invasive disease may spread to regional lymph nodes (LNs) and other organs, including the bones, liver and lungs $(3,4)$. Surgery is usually the first-line treatment for primary EMPD, but no standard treatment regimen for metastatic disease has been established.

Positron emission tomography/computed tomography (PET/CT) is a widely used imaging modality that is capable of detecting metastatic tumors in various organs. There have been several case reports on the use of PET/CT in LN-metastatic EMPD cases. These previous studies have revealed that the maximum standardized uptake value (SUVmax) may be useful for detecting nodal metastasis in EMPD cases (3,5-7).

Histologically, EMPD is closely associated with Paget's disease of the mammary gland; in almost all cases of the latter, human epidermal growth factor receptor 2 (HER2) is amplified and overexpressed (8). In breast cancer, HER2 overexpression 
is correlated with aggressive disease and serves as a biomarker for the use of HER2-targeted therapy (9). Various studies have shown that $15-60 \%$ of patients with EMPD harbor HER2 protein overexpression and gene amplification (10-12). Several case reports of HER2-targeted trastuzumab monotherapy for EMPD patients with HER2 overexpression have described prolongation of the median progression-free survival (PFS) time from 6 to $12-17$ months $(13,14)$. However, knowledge regarding gene amplification and mutation of HER2 in LN-metastatic penoscrotal EMPD is limited. As the therapeutic efficacy of HER2-targeted therapy is dependent on the overexpression and gene amplification of HER2, further study is required.

In the present study, the association between LN metastasis and PET/CT was evaluated, as well as the role of HER2 amplification as a biomarker for treatment in patients with LN-metastatic penoscrotal EMPD. The efficacy of trastuzumab was assessed in 2 patients.

\section{Patients and methods}

Patients. The present study was approved by the Ethical Committee of Fudan University Shanghai Cancer Center (FUSCC; Shanghai, China). Written informed consent was obtained from the patients. A total of 11 male patients with LN-metastatic EMPD on the scrotum, who were treated at FUSCC between January 2009 and January 2016, were retrospectively reviewed. Patients who did not undergo surgery were excluded. A PET/CT scan was conducted on each of them prior to surgery, during which the primary lesion and lymph nodes were excised.

Clinicopathological characteristics, including age, metastatic sites, PFS and PET/CT scan results, were obtained from electronic records. Patients were regularly followed up by telephone or in the clinic every 3 months. Physical and radiographic examinations were retrieved from electronic medical records. Patients who had follow-up in their local hospital sent the information via the internet. With regard to patients who were followed up by phone, their vital status was followed using scheduled phone calls, independent of their physician. Events such as tumor recurrence, progression and metastasis were recorded.

Circulating tumor DNA was also conducted in one of the cases (case No. 11). A blood sample was taken from the patient and sent to BGI company (The Beijing Genomic institute, Beijing, China). BGISEQ-500 platform (http://www.genomics. $\mathrm{cn} /$ navigation/show_navigation?nid=4201) was used to get the results.

Immunohistochemistry (IHC) and fluorescence in situ hybridization (FISH). IHC and FISH were used to evaluate HER2 gene amplification in samples from LNs according to the American Society of Clinical Oncology/College of American Pathologists guidelines (15). Dual-probe ISH assays were conducted and HER2 amplification was defined by examining the HER2/chromosome enumeration probe 17 (CEP17) ratio followed by the mean HER 2 copy number (15). The probe used in the FISH test was from the PathVysion HER2 DNA Probe kit (Abbott Laboratories, Abbott Park, Chicago, IL, USA).
Mutation analysis. Samples of dissected LNs were stored at $-80^{\circ}$ in the tissue bank at FUSCC. Genomic DNA was extracted using a TIANamp Genomic DNA kit (Tiangen Biotech Co., Ltd., Beijing, China). Polymerase chain reaction (PCR) was performed on all DNA samples. The intron-based primers for 7 exons of the tyrosine kinase domain and exon 8 of the extracellular domain of HER2 were used according to a previous study (16). Distilled water was used as a negative control for the PCR. Primer sequences are shown in Table I. The denaturation, annealling and extension temperature was 95, 58 and $72^{\circ} \mathrm{C}$ (32 cycles), respectively. All PCR products were subjected to direct sequencing using an Applied Biosystems 3730xL DNA sequencer (Thermo Fisher Scientific, Inc., Waltham, MA, USA).

Statistical analysis. PFS time was calculated from the date of surgery to the progression of the disease. Patients without events or mortality were recorded as censored at the time of last follow-up. SPSS 22.0 software (IBM Corp., Armonk, NY, USA) was used to perform the statistical analysis. PFS was analyzed using the Kaplan-Meier method, with log-rank tests used to assess the differences between the groups. A two-sided P-value of $<0.05$ was considered to indicate a statistically significant difference.

\section{Results}

Demographic information and diagnostic performance of PET/CT in patients with penoscrotal EMPD with LN metastasis. A total of 11 patients were included in the present study. The median age of these patients was 63 years (range, 48-76 years). Of these patients, 6 were diagnosed with EMPD and 5 were diagnosed with underlying apocrine carcinoma with epidermal manifestation of EMPD (Table II).

All patients underwent surgical treatment of the primary lesion and the affected LNs. PET/CT was performed on each patient in the month prior to dissection of the LNs. The mean size of the metastatic LNs on PET/CT was $2.3 \mathrm{~cm}$. The mean SUVmax of the metastatic LNs was 7.2. Generally, the PET/CT results were highly associated with the pathology. A false-negative case (no. 11) of inguinal LNs and a false-negative case (no. 6) of pelvic LNs were identified using PET/CT (Tables III and IV). Although LN metastases were not identified in these 2 cases, the patients had invasive EMPD, which was strongly associated with LN metastasis in our previous study (3); therefore, a prophylactic LN dissection was discussed with the patients and they each accepted the surgical intervention. The sensitivity and specificity of PET/CT was 90.9 and $100.0 \%$ for inguinal LNs, and 85.7 and $80.0 \%$ for pelvic LNs, respectively.

The median time from LN dissection to disease progression (LN progression or novel LN metastasis or distant metastasis) was $15.9 \pm 1.5$ months (primary site without vs. with underlying carcinoma, 16.2 vs. 14.6 months, respectively). The median time from discovery of the primary disease to LN metastasis was $12.0 \pm 2.3$ months (primary site without vs. with underlying carcinoma; 12.0 vs. 6.0 months, respectively). Primary sites with underlying carcinoma were indicated to be more aggressive.

Outcome of penoscrotal EMPD in patients with LN metastasis treated with regional $L N$ dissection. Following discovery 
Table I. Primers for mutation analysis of human epidermal growth factor receptor 2 gene.

\begin{tabular}{lll}
\hline Exon & \multicolumn{1}{c}{ Forward primer $\left(5^{\prime}-3^{\prime}\right)$} & Reverse primer $\left(5^{\prime}-3^{\prime}\right)$ \\
\hline 8 & TCTACTCTCTACCCCTGGCC & ACTTCTGTCTCCTGCCATCC \\
18 & CAGTTACAGCGGAGAAGGGA & AGTCTAGGTTTGCGGGAGTC \\
19 & GCTGGTACTTTGAGCCTTCA & CCCAGCAAGAGTCCCCAT \\
20 & AGCAAACCCCTATGTCCACA & TGGGAGGGCAGAAGAGGA \\
21 & TGAAGGACCAAGGAGCAGAG & CTCCCTTCACATGCTGAGGT \\
22 & TCTCCTGGCATCACATCTCC & GGGCTCCTGGGTCTACATAC \\
23 & GTGCTACTTCTCTACCACCTGA & TTCTGTGGAGGAAGGAGAGG \\
24 & CATCCTGCCTCTCCTTCCTC & ACAGTGTGACCGAGGGCA
\end{tabular}

Table II. Clinicopathological features of the patients.

\begin{tabular}{lcc}
\hline Feature & HER2-negative & HER2-positive \\
\hline $\begin{array}{l}\text { Number of patients } \\
\text { Median age, years }\end{array}$ & $83.5 \pm 6.3$ & 3 \\
Pathology & & $54.0 \pm 13.2$ \\
EMPD, n (\%) & $5(62.5)$ & $1(33.3)$ \\
EMPD with underlying & $3(37.5)$ & $2(66.7)$ \\
carcinoma, n (\%) & & \\
Lymph node metastasis & & $3(100.0)$ \\
Inguinal, n (\%) & $8(100.0)$ & $3(100.0)$ \\
Pelvic, n $(\%)$ & $4(50.0)$ & 13.6 \\
PFS1 ${ }^{\mathrm{a}}$, months & 16.2 & 10.0 \\
PFS2 $^{\mathrm{b}}$, months & 15.6 & \\
\hline
\end{tabular}

${ }^{a}$ Time from lymph node dissection to the progression of the disease; ${ }^{b}$ time from discovery of the disease to lymph node metastasis. HER2, human epidermal growth factor receptor 2; EMPD, extramammary Paget's disease; PFS, progression-free survival.

or treatment of the primary lesion, all patients developed inguinal LN metastasis; 6 (54.5\%) patients also developed pelvic LN metastasis (Table II). LN progression was identified in case no. 10 and 11 , in 1 patient with lung metastasis and in 1 patient with liver metastasis. During the postoperative follow-up, 2 patients exhibited no recurrence of the disease. The disease-free survival times of these 2 patients were 16.2 and 54.8 months, respectively.

Adjuvant chemotherapy was administered to 3 patients. Following disease progression, different chemotherapy regimens were used as shown in Table V. The PFS of chemotherapy ranged from 3-16 months.

HER2 amplification and mutation analysis in patients with LN metastasis, and subsequent targeted therapy. Out of 11 patients, 3 (27.3\%) were HER2-positive. IHC results are listed in Table III and shown in Fig. 1. Patients with HER 2 amplification showed a trend for shorter median times from disease discovery to LN metastasis (15.6 vs. 10.0 months) and from LN dissection to disease progression (16.2 vs. 13.6 months), although no statistically significant difference was observed due to the limited number of samples (Table II).

A previous study has indicated that the majority of HER2 mutational sites are clustered in two major regions of the gene. Overall, $20 \%$ of patients have extracellular domain mutations at residues 309 and 310, and 68\% have kinase domain mutations between residues 755 and 781 (17). Therefore, in all 11 samples, the region of exon 8, including residues 309 and 310 , and the 7 exons of the entire HER 2 tyrosine kinase domains were sequenced. No HER2 mutations were identified. Trastuzumab-targeted therapy was administered to 2 of the patients with HER2 amplification with successful outcomes.

Case 1. A 48-year-old man presented with scrotal erythema and was admitted to the FUSCC in February 2014. A CT scan showed metastatic LNs in the left inguinal. Pathomorphology of biopsy specimens were consistent with EMPD with underlying carcinoma. The patient underwent a wide local tumor resection with left inguinal and pelvic lymphadenectomy in February 2014. However, PET/CT revealed recurrence with left external iliac, retroperitoneal and right inguinal lymphadenopathy in August 2014. Examination of a biopsy specimen from the enlarged right inguinal LNs confirmed recurrence of the disease, and FISH analysis revealed HER2 gene amplification (Fig. 2).

Trastuzumab targeted therapy was administered at a maintenance dose of $2 \mathrm{mg} / \mathrm{kg}$ on days 1,8 and 15 , together with chemotherapy $\left(80 \mathrm{mg} / \mathrm{m}^{2}\right.$ paclitaxel and $30 \mathrm{mg} / \mathrm{m}^{2}$ cisplatin on days 1, 8 and 15) every 3 weeks. Following 4 cycles of treatment, a complete response was obtained with regression of the iliac lymph node (Fig. 3), and the disease remained stable until January 2016, when magnetic resonance imaging showed enlarged LNs in the retroperitoneum. The follow-up was performed once every 3 months. The PFS time following first-line trastuzumab monotherapy was almost 17 months.

Case 2. A 54-year-old man was diagnosed with EMPD in June, 2013. Extensive resection of the primary lesion was performed. Disease recurrence was identified in August, 2014 and a second surgery together with adjuvant radiation therapy was conducted. The disease remained stable until December 2015, when PET/CT revealed left external iliac lymphadenopathy with an SUVmax of 5.2; swelling of a left inguinal LN was also observed. The patient underwent left inguinal and pelvic lymphadenectomy in January 2016. Pathological examination showed left external iliac and left inguinal 


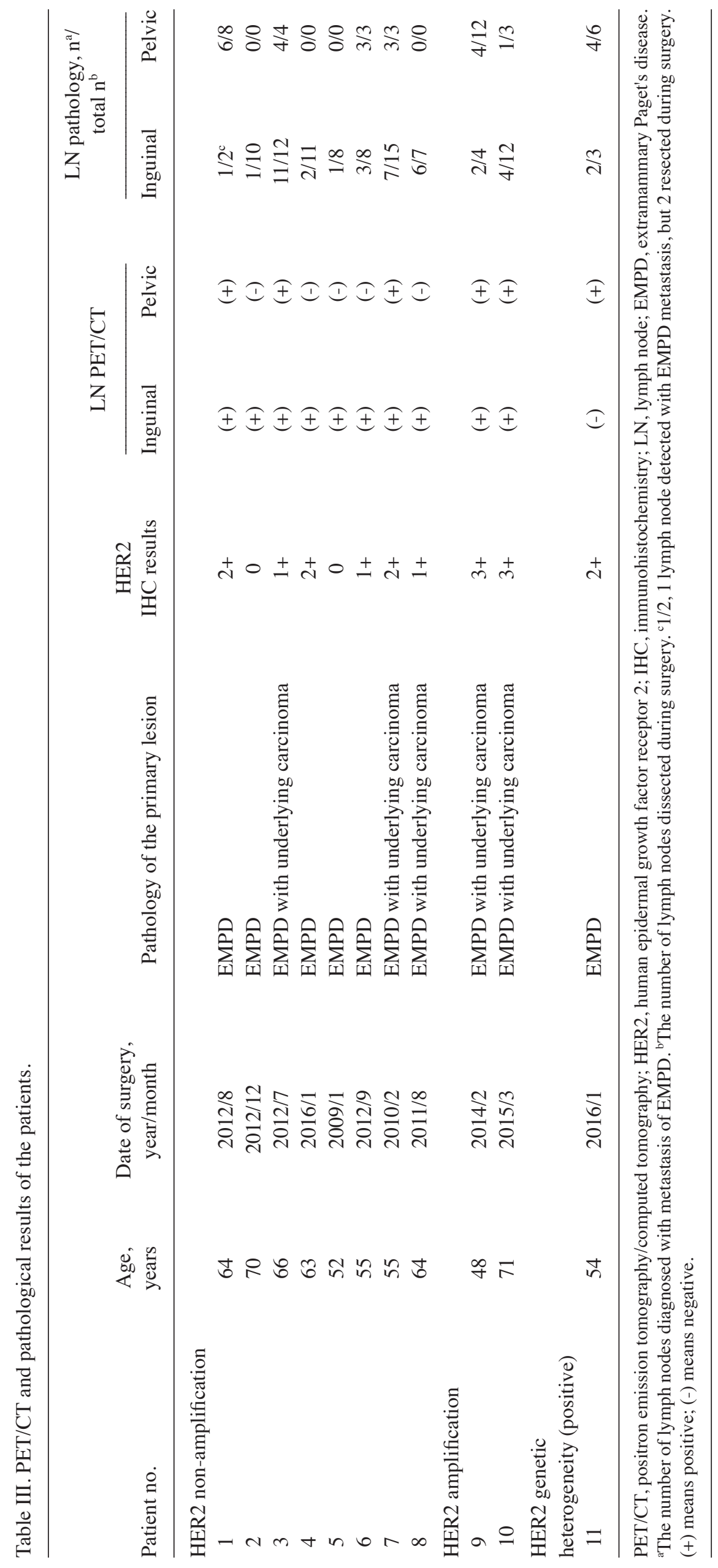


Table IV. Positive detection of LN metastases by PET/CT and pathology.

\begin{tabular}{lcc}
\hline LN & PET/CT & Pathology \\
\hline Inguinal, n & 10 & 11 \\
Pelvic, $n$ & 6 & 7 \\
\hline
\end{tabular}

LN, lymph node; PET/CT, positron emission tomography/computed tomography.

lymphadenopathy. Subsequent to the surgery, the patient received 4 cycles of chemotherapy with docetaxel $\left(75 \mathrm{mg} / \mathrm{m}^{2}\right)$ and cisplatin $\left(30 \mathrm{mg} / \mathrm{m}^{2}\right)$ every 3 weeks. In February 2017, the patient developed headaches and chest discomfort. Another PET/CT showed multiple metastatic sites in the liver and bones. FISH analysis revealed HER2 genetic heterogeneity (Fig. 4). The HER2/CEP17 ratio was $>2.0$ for $10 \%$ of infiltrating tumor cells. The mean HER $2 /$ CEP17 ratio was 1.9 , but $>4$ copies of HER2 per cell were observed. Therefore, this patient was considered to possess a positive result for HER2 amplification. Trastuzumab targeted therapy was administered at a dose of $360 \mathrm{mg}$ every 3 weeks together with paclitaxel $\left(80 \mathrm{mg} / \mathrm{m}^{2}\right)$ every week. Following 2 cycles of trastuzumab and 9 cycles of paclitaxel, the disease remained stable for 5 months. In August 2017, the patient felt lumbar pain and another PET/CT revealed regression of the initial sites of liver metastases and those at certain bone sites. Also novel bone metastatic sites and progression were identified.

A blood sample was taken from the patient. Sequencing of circulating tumor DNA was conducted following the failure of the treatment, and human epidermal growth factor receptor 3 (HER3) mutation was identified at a rate of $0.6 \%$. This may explain why the patient experienced resistance to trastuzumab. The patient was then treated with lapatinib and capecitabine.The follow-up was performed once every 3 months and the patient had stable disease at last follow-up on January 2018.

Literature review of the prevalence of HER2 amplification in patients with EMPD and efficacy of HER2-targeted therapy. A literature review of studies that investigated the prevalence of HER 2 amplification in patients with EMPD was conducted (Table VI). Altogether, 485 cases of EMPD were reported and 35 of them had metastases. Overall, $20.7 \%$ of patients with EMPD exhibited HER2 amplification. In addition, the probability of HER 2 amplification was more notable in patients with metastatic EMPD. A slight increase in the percentage of HER2 positivity was observed when metastatic disease samples were assessed for HER2 gene amplification.

The published case reports regarding the efficacy of HER2-targeted therapy in EMPD patients with HER2 amplification are summarized in Table VII. These cases, including the present study, included a total of 10 patients. All patients showed a marked response to targeted therapy, including 4 with the complete remission of metastatic disease. The median PFS time was $>12$ months. None of the patients developed severe adverse effects during treatment.

\section{Discussion}

In this study, 11 cases of penoscrotal EMPD were evaluated. HER2 gene amplification was present in 3 (27.3\%) patients, and 1 showed genetic heterogeneity. A PET/CT-surgery-HER2 testing modality may serve as a good treatment regimen for patients with LN-metastatic penoscrotal EMPD.

Generally, EMPD has a favorable prognosis, as the majority of cases are accompanied by carcinoma in situ. However, once the disease has invaded the subcutaneous tissue or has spread to the LNs or distant sites, the prognosis is poor. Invasive disease, positive margins, lymphovascular invasion and LN metastasis are negative prognostic factors. As metastatic EMPD is quite rare, no clinical trials have been performed to determine the standard treatment regimen. Cytotoxic agents, including cisplatin, epirubicin, 5-fluorouracil, mitomycin C, docetaxel and paclitaxel, have shown some effect. However, the prognosis remains poor, with the median survival time ranging from 9 to 12 months $(18,19)$.

HER2 gene amplification has been correlated with more aggressive breast cancer, leading to the era of targeted therapy in cancer management (20). In the present study, the clinical behavior of HER2-positive scrotal EMPD appeared to be similar to that of HER2-positive breast cancer, with a shorter time from the onset of primary disease to LN metastasis (21).

One study of EMPD has also shown that HER2-positive tumors at the primary site have more aggressive clinical behavior, including frequent metastasis to LNs or deep invasion (12). This suggests that EMPD and HER2-positive breast cancer share common features and that HER2-targeted therapies such as trastuzumab monotherapy may also be effective in patients with HER2 gene amplification in advanced scrotal EMPD.

In the present study, PET/CT was performed immediately prior to surgery for each of the patients and showed a high association with the final pathology. Previous studies have revealed that regardless of LN swelling, the SUVmax of $\mathrm{LN}$-positive cases is significantly higher compared with that of LN-negative cases (22). A study of 33 patients showed that the sensitivity and specificity of PET/CT in detecting metastatic LNs were 75.0 and $96.4 \%$, respectively (23). In comparison, the positivity rate for sentinel LN biopsy is only $\sim 50 \%$ in patients with $\mathrm{LN}$ swelling $(24,25)$. Therefore, $\mathrm{PET} / \mathrm{CT}$ is recommended for cases in which LN metastasis is suspected.

In the present study, 11 rare cases of LN metastatic scrotal EMPD were evaluated. IHC and FISH analysis were used to evaluate the HER2 status of the patients, thus avoiding variations due to tissue fixation and processing.

All patients underwent surgery for the primary lesion and metastatic LNs. Few reports of the effect of surgery on metastatic or advanced EMPD have been published. Based on the current results in patients with inguinal or pelvic LN metastatic EMPD, PET/CT can produce false-negative results, and therefore, surgery can improve the local control of the tumor and define the disease stage. Additionally, HER2 status can be obtained from LN specimens, which may be used to guide subsequent treatment. In the present study, the median time from LN dissection to disease progression was $15.9 \pm 1.5$ months. No recurrence was identified in 2 of the 
Table V. Progression and treatment choices.

\begin{tabular}{|c|c|c|c|c|}
\hline Patient no. & $\begin{array}{l}\text { Recurrent or metastatic } \\
\text { site following surgery }\end{array}$ & $\begin{array}{c}\text { Adjuvant } \\
\text { chemotherapy }\end{array}$ & $\begin{array}{l}\text { Therapy } \\
\text { following progression }\end{array}$ & $\begin{array}{c}\text { Progression-free } \\
\text { survival following } \\
\text { chemotherapy, months }\end{array}$ \\
\hline \multicolumn{5}{|c|}{ HER2 } \\
\hline \multicolumn{5}{|c|}{ non-amplification } \\
\hline 1 & None $^{a}$ & None $^{a}$ & None $^{a}$ & None $^{a}$ \\
\hline 2 & $\begin{array}{l}\text { Left neck, left supraclavicular, } \\
\text { mediastinum, retroperitoneum } \\
\text { and left iliac LN }\end{array}$ & None & $\begin{array}{l}\text { Dose-dense methotrexate, } \\
\text { vinblastine, doxorubicin } \\
\text { and cisplatin }\end{array}$ & None $^{a}$ \\
\hline 3 & $\begin{array}{l}\text { Retroperitoneum, right iliac and } \\
\text { left thigh muscle gap LN }\end{array}$ & None & Docetaxel and cisplatin & 6 \\
\hline 4 & No recurrence & None & None & None \\
\hline 5 & $\begin{array}{l}\text { Right supraclavicular, } \\
\text { mediastinum and retroperitoneum } \\
\text { LN, and lung }\end{array}$ & $\begin{array}{l}\text { Bleomycin A5 } \\
\text { and cisplatin }\end{array}$ & $\begin{array}{l}\text { Docetaxel, cisplatin, } \mathrm{CF} \\
\text { and } 5 \mathrm{FU}\end{array}$ & 16 \\
\hline 6 & No recurrence & None & None & None \\
\hline 7 & $\begin{array}{l}\text { Primary site, retroperitoneum, } \\
\text { right inguinal and right iliac LN }\end{array}$ & $\begin{array}{l}\text { Docetaxel and } \\
\text { cisplatin }\end{array}$ & $\mathrm{CF}, 5 \mathrm{FU}$ and oxaliplatin & 6 \\
\hline 8 & Primary site & None & 5FU and cisplatin & 10 \\
\hline \multicolumn{5}{|c|}{$\begin{array}{l}\text { HER } 2 \\
\text { amplification }\end{array}$} \\
\hline 9 & $\begin{array}{l}\text { Left external iliac, retroperitoneal } \\
\text { and right inguinal lymphadenopathy }\end{array}$ & None & $\begin{array}{l}\text { Trastuzumab, paclitaxel } \\
\text { and cisplatin }\end{array}$ & 17 \\
\hline 10 & $\begin{array}{l}\text { Retroperitoneum, iliac and } \\
\text { inguinal LN and bone }\end{array}$ & None & Docetaxel and cisplatin & $3^{\mathrm{a}}$ \\
\hline \multicolumn{5}{|c|}{$\begin{array}{l}\text { HER2 genetic } \\
\text { heterogeneity }\end{array}$} \\
\hline 11 & Liver and bone & $\begin{array}{l}\text { Docetaxel and } \\
\text { cisplatin }\end{array}$ & $\begin{array}{l}\text { Trastuzumab and } \\
\text { paclitaxel }\end{array}$ & 5 \\
\hline
\end{tabular}

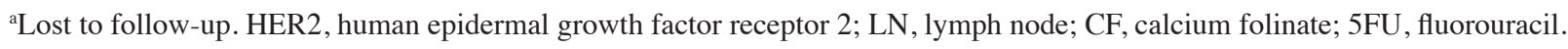

patients during the follow-up and these patients had a favorable outcome.

Furthermore, 2 patients exhibited different treatment outcomes following trastuzumab monotherapy. A complete response was observed in 1 case in which LN pathology showed HER2 amplification, while 1 patient with HER2 genetic heterogeneity remained stable following monotherapy. This result indicates that the number of infiltrating tumor cells with an HER2/CEP17 ratio of $>2.0$ may serve as a predictive marker for treatment outcome in patients with EMPD with HER2 amplification. Also, HER3 mutation was identified in the circulating tumor DNA of a patient (case No. 11) with less effective treatment outcome. HER3, can drive HER2-mediated phosphoinositide 3-kinase signaling, which serves a critical role in tumor cell survival, proliferation, invasion, migration, cellular metabolism and angiogenesis (26). In breast cancer, HER3 overexpression predicts resistance to trastuzumab and lapatinib $(27,28)$. This may explain the failure of the treatment in the patient with a HER3 mutation in the present study. Meanwhile, platinum-based therapies combined with paclitaxel or docetaxel may be an effective treatment option for HER2-negative patients.
The present study has several limitations. Relatively few patients were included due to the rarity of the disease. All cases were retrospectively reviewed and were from a single institution. Different chemotherapy regimens were applied following disease progression, which may have influenced the PFS time. Further studies involving more cases are required.

In conclusion, PET/CT may be useful for detecting nodal metastases in all EMPD patients. EMPD may be effectively treated with HER2-targeted agents. The present data combined with that of case reports from the literature provide a basis for HER2 testing in this rare disease and warrant a multicenter study to compare trastuzumab with conventional treatment.

\section{Acknowledgements}

Not applicable.

\section{Funding}

No funding was received. 
A

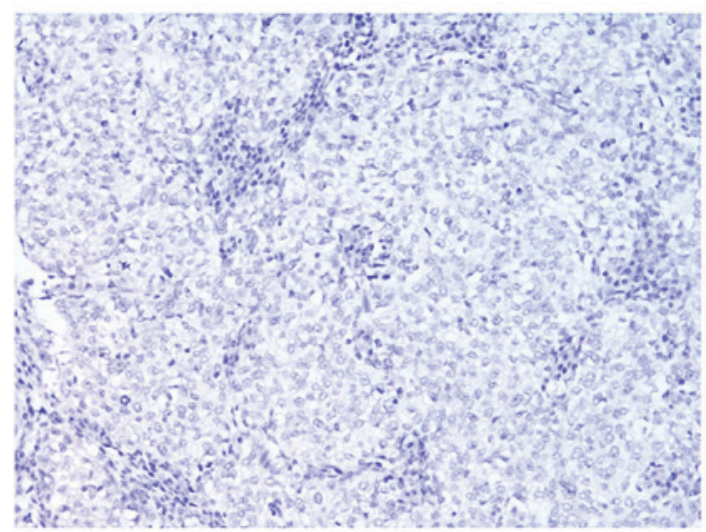

C

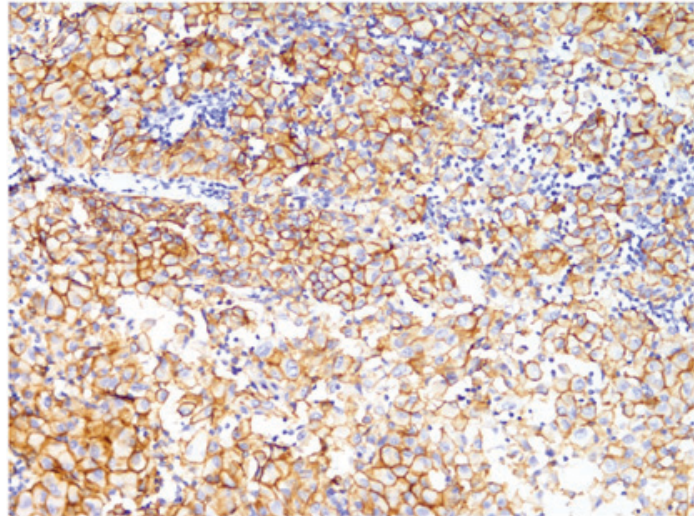

$\mathrm{B}$

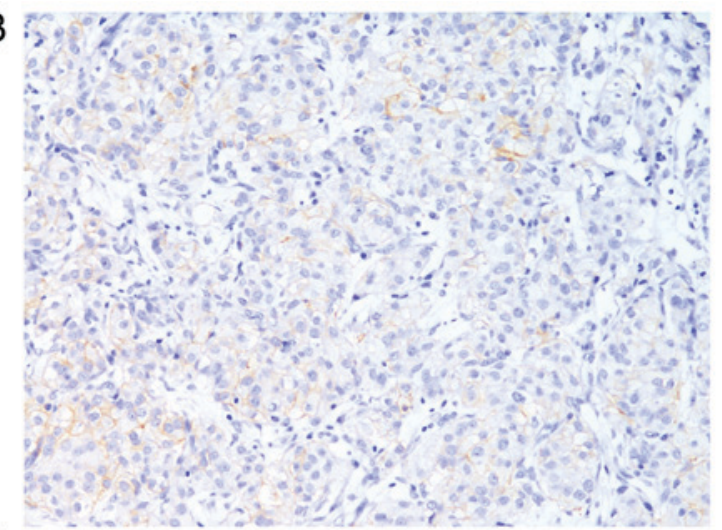

D

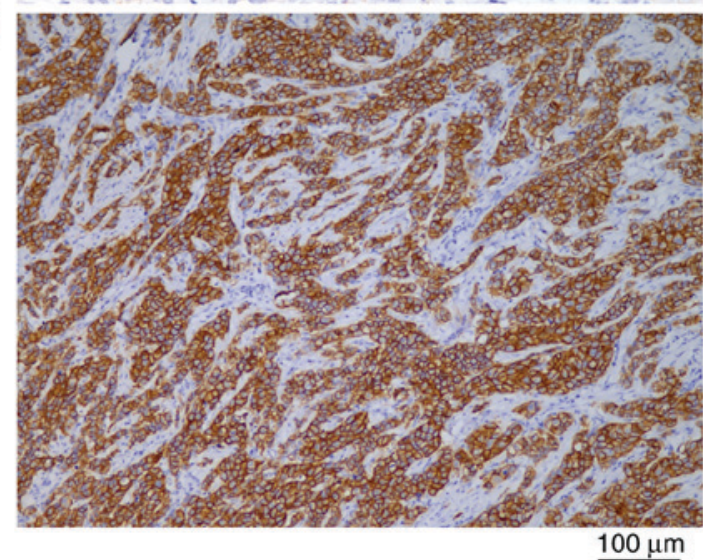

Figure 1. Immunohistochemistry in samples of lymph nodes from cases of extramammary Paget's disease cases. The brown staining indicates the intensity and distribution of cell membrane HER2 protein expression. (A) HER2-negative case; (B) HER2 1+ case; (C) HER2 2+ case; (D) HER2 3+ case. HER2, human epidermal growth factor receptor 2.

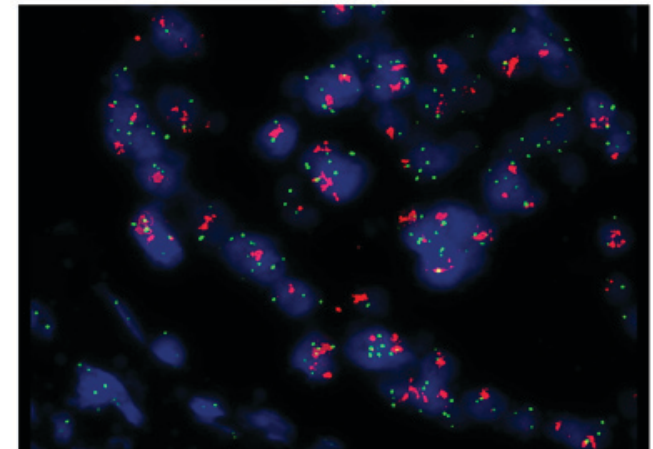

Figure 2. HER2 amplification in a tumor sample from a patient with extramammary Paget's disease (case 1) revealed by FISH analysis. The red HER2 and green CEP-17 signals were counted on the background of tumor cells (the blue staining). The red and green signals represent the copy number of HER2 gene and chromosome 17, respectively. The HER $2 /$ chromosome enumeration probe 17 ratio was >2.0. HER2, human epidermal growth factor receptor 2 .

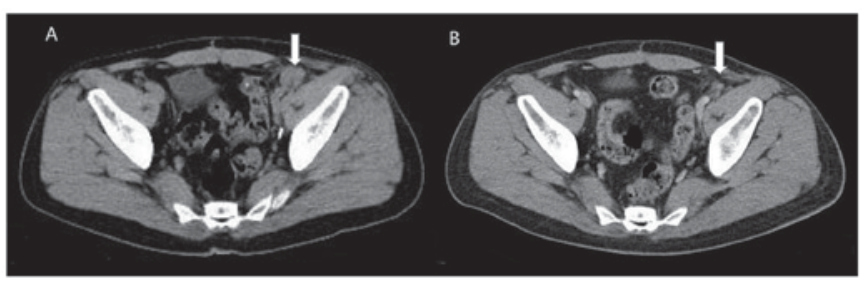

Figure 3. Regression of the iliac lymph node (arrow) following trastuzumab therapy in a patient with extramammary Paget's disease (case 1). Computed tomography scan of the pelvic area, (A) prior to and (B) following treatment.

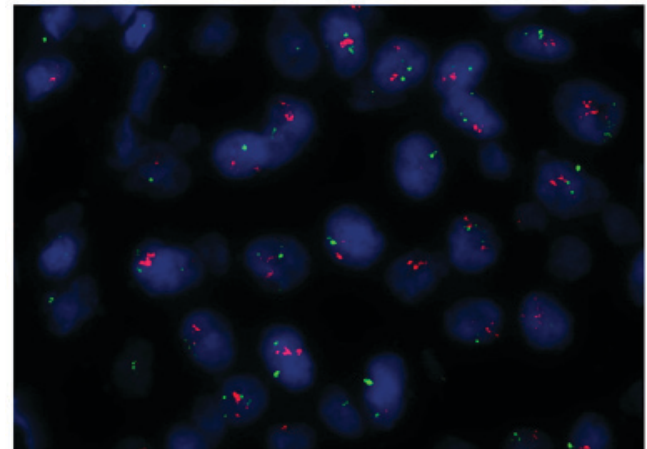

Figure 4. HER2 genetic heterogeneity in a tumor sample from a patient with extramammary Paget's disease (case 2) revealed by FISH analysis. The red HER2 and green CEP-17 signals were counted on the background of tumor cells (the blue staining). The HER2/CEP17 ratio was $>2.0$ in $10 \%$ of infiltrating tumor cells. HER2, human epidermal growth factor receptor 2; CEP17, chromosome enumeration probe 17.

\section{Availability of data and materials}

All data generated or analyzed during this study are included in this published article.

\section{Authors' contributions}

YZ and DY designed the study. XL participated in manuscript writing, data analysis, HER2 mutation testing and patient 
Table VI. Prevalence of HER2 amplification in metastatic extramammary Paget's disease.

\begin{tabular}{|c|c|c|c|c|c|c|c|c|}
\hline First author & Year & $\begin{array}{l}\text { No. of } \\
\text { patients }\end{array}$ & Primary site & $\begin{array}{l}\text { Stage of } \\
\text { disease }\end{array}$ & $\begin{array}{l}\text { Disease } \\
\text { detected }\end{array}$ & $\begin{array}{l}\text { Detection } \\
\text { methods }\end{array}$ & $\begin{array}{l}\text { No. with HER2 } \\
\text { amplification, } \\
\mathrm{n}(\%)\end{array}$ & (Refs.) \\
\hline Tanskanen et al & 2003 & 23 & Skin & Localized & Primary & IHC, FISH & $10(43.5)$ & (29) \\
\hline Reich et al & 2005 & 6 & Vulva & Recurrent & Primary & FISH & $4(66.7)$ & (30) \\
\hline Ogawa et al & 2005 & 36 & Perineum & Localized & Primary & $\mathrm{IHC}$ & $3(8.3)$ & (31) \\
\hline Plaza et al & 2009 & 47 & $\begin{array}{l}6 \text { scrotum, } 7 \text { perianal } \\
\text { region, } 1 \text { axilla and } \\
33 \text { vulva }\end{array}$ & Localized & Primary & IHC & $6(12.7)$ & (32) \\
\hline \multirow[t]{2}{*}{ Miyamoto et al } & 2010 & 23 & $\begin{array}{l}28 \text { genital, } 2 \text { genital } \\
\text { and perianal, } \\
1 \text { perianal and } \\
1 \text { axillary }\end{array}$ & Localized & Primary & IHC, FISH & $13(56.5)$ & (33) \\
\hline & & 9 & & Metastatic & Primary & & 7 (77.8) & (33) \\
\hline Tanaka et $a l^{\mathrm{a}}$ & 2013 & $\begin{array}{l}78 \\
26\end{array}$ & Skin & $\begin{array}{l}\text { Localized } \\
\text { Metastatic }\end{array}$ & $\begin{array}{l}\text { Primary } \\
\text { Primary }\end{array}$ & IHC, FISH & $\begin{array}{l}8(10.3) \\
5(19.2)\end{array}$ & (12) \\
\hline \multirow[t]{2}{*}{ Kang et al } & 2015 & 227 & $\begin{array}{l}211 \text { scrotum, } \\
15 \text { penile shaft, } \\
14 \text { pubic area and } \\
\text { groin }\end{array}$ & Localized & Primary & IHC & $45(18.3)$ & (34) \\
\hline & & 19 & & Metastatic & & & & \\
\hline Tanaka et $a l^{\mathrm{a}}$ & 2016 & 26 & Skin & Metastatic & Metastatic & IHC, FISH & $5(19.2)$ & (35) \\
\hline $\begin{array}{l}\text { Hikita et al } \\
\text { The present study }\end{array}$ & 2012 & $\begin{array}{l}17 \\
11\end{array}$ & $\begin{array}{l}\text { Genital } \\
\text { Scrotum }\end{array}$ & $\begin{array}{l}\text { Primary } \\
\text { Metastatic }\end{array}$ & $\begin{array}{l}\text { Primary } \\
\text { Metastatic }\end{array}$ & $\begin{array}{l}\text { IHC, FISH } \\
\text { FISH }\end{array}$ & $\begin{array}{l}4(23.5) \\
3(27.2)\end{array}$ & (36) \\
\hline
\end{tabular}

${ }^{a}$ These 2 studies are from the same center and same cohort. HER2, human epidermal growth factor receptor 2; IHC, immunohistochemistry; FISH, fluorescence in situ hybridization.

Table VII. Efficacy of human epidermal growth factor receptor 2-targeted therapy.

\begin{tabular}{|c|c|c|c|c|c|}
\hline First author & Year & Treatment modality & Effect & PFS, months & (Refs.) \\
\hline Karam et al & 2008 & Trastuzumab (300 mg qm) & PR & 12 & $(37)$ \\
\hline Takahagi et al & 2009 & $\begin{array}{l}\text { Trastuzumab, } 4 \mathrm{mg} / \mathrm{kg} \text { followed } \\
\text { by } 2 \mathrm{mg} / \mathrm{kg} \text { qw, and paclitaxel }\left(80 \mathrm{mg} / \mathrm{m}^{2} \mathrm{qw}\right)\end{array}$ & PR & 6 & $(38)$ \\
\hline Hanawa et al & 2011 & $\begin{array}{l}\text { Trastuzumab, } 4 \mathrm{mg} / \mathrm{kg} \text { followed by } 2 \mathrm{mg} / \mathrm{kg} \text { qw, } \\
\text { and paclitaxel }\left(80 \mathrm{mg} / \mathrm{m}^{2} \mathrm{qw}\right)\end{array}$ & PR & 14 & $(39)$ \\
\hline Wakabayashi et al & 2012 & Trastuzumab, $8 \mathrm{mg} / \mathrm{kg}$ followed by $6 \mathrm{mg} / \mathrm{kg}$ q3w & CR & $>13^{\mathrm{a}}$ & (13) \\
\hline Yoshimura et al & 2013 & Trastuzumab, $4 \mathrm{mg} / \mathrm{kg}$ followed by $2 \mathrm{mg} / \mathrm{kg}$ qw & PR & 4 & $(40)$ \\
\hline Barth et al & 2015 & Trastuzumab, $8 \mathrm{mg} / \mathrm{kg}$ followed by $6 \mathrm{mg} / \mathrm{kg}$ q3w & CR & $>12^{\mathrm{a}}$ & (41) \\
\hline Zhang et al & 2015 & Trastuzumab, $6 \mathrm{mg} / \mathrm{kg} \mathrm{q} 3 \mathrm{w}$ & PR & $>15^{\mathrm{a}}$ & $(42)$ \\
\hline Shin et al & 2016 & $\begin{array}{l}\text { Trastuzumab/docetaxel/carboplatin followed by } \\
\text { maintenance trastuzumab }\end{array}$ & $\mathrm{CR}$ & Not reported ${ }^{a}$ & (43) \\
\hline Watanabe et al & 2016 & $\begin{array}{l}\text { Trastuzumab, } 8 \mathrm{mg} / \mathrm{kg} \text { followed by } 6 \mathrm{mg} / \mathrm{kg} \mathrm{q} 3 \mathrm{w} \text {, } \\
\text { docetaxel, } 75 \mathrm{mg} / \mathrm{m}^{2} \mathrm{q} \text { and pertuzumab, } \\
840 \mathrm{mg} / \mathrm{m}^{2} \text {, followed by } 420 \mathrm{mg} / \mathrm{m}^{2} \mathrm{q} 3 \mathrm{w}\end{array}$ & PR & 12 & (14) \\
\hline
\end{tabular}

${ }^{a}$ These studies did not report the endpoint. PR, partial response; CR, complete response; PFS, progression-free survival; qm, once a month; $\mathrm{q} 3 \mathrm{w}$, once every 3 weeks; qw, once a week. 
follow-up. PZ took part in HER2 FISH and IHC testing, as well as data collection.

\section{Ethics approval and consent to participate}

The study was approved by the Ethical Committee of Fudan University Shanghai Cancer Center. Written informed consent was obtained from each of the patients.

\section{Patient consent for publication}

Every patient was asked to sign a consent form confirming that their blood sample, tissue after the surgery and clinical information would be used for research purposes when they were admitted to hospital.

\section{Competing interests}

The authors declare that they have no competing interests.

\section{References}

1. Kyriazanos ID, Stamos NP, Miliadis L, Noussis G and Stoidis CN Extra-mammary Paget's disease of the perianal region: A review of the literature emphasizing the operative management technique. Surg Oncol 20: e61-e71, 2011.

2. Wagner G and Sachse MM: Extramammary Paget disease-clinical appearance, pathogenesis, management. J Dtsch Dermatol Ges 9 : 448-454, 2011 (In English, German).

3. Zhu Y, Ye DW, Yao XD, Zhang SL, Dai B, Zhang HL, Shen YJ and Mao HR: Clinicopathological characteristics, management and outcome of metastatic penoscrotal extramammary Paget's disease. Br J Dermatol 161: 577-582, 2009.

4. Dai B, Kong YY, Chang K, Qu YY, Ye DW, Zhang SL and Zhang HL: Primary invasive carcinoma associated with penoscrotal extramammary Paget's disease: A clinicopathological analysis of 56 cases. BJU Int 115: 153-160, 2015.

5. Cho SB, Yun M, Lee MG and Chung KY: Variable patterns of positron emission tomography in the assessment of patients with extramammary Paget's disease. J Am Acad Dermatol 52: 353-355, 2005.

6. Niederkohr RD and Gambhir SS: F-18 FDG PET/CT imaging of extramammary Paget disease of the perianal region. Clin Nucl Med 31: 561-563, 2006.

7. Fujiwara M, Suzuki T, Senoo A, Fukamizu H and Tokura Y: Evaluation of positron emission tomography imaging to detect lymph node metastases in patients with extramammary Paget's disease. J Dermatol 44: 939-943, 2017.

8. Meissner K, Riviere A, Haupt G and Löning T: Study of neu-protein expression in mammary Paget's disease with and without underlying breast carcinoma and in extramammary Paget's disease. Am J Pathol 137: 1305-1309, 1990.

9. von Minckwitz G, du Bois A, Schmidt M, Maass N, Cufer T, de Jongh FE, Maartense E, Zielinski C, Kaufmann M, Bauer W, et al: Trastuzumab beyond progression in human epidermal growth factor receptor 2-positive advanced breast cancer: A german breast group 26/breast international group 03-05 study. J Clin Oncol 27: 1999-2006, 2009.

10. Brummer O, Stegner HE, Bohmer G, Kühnle H and Petry KU: HER-2/neu expression in Paget disease of the vulva and the female breast. Gynecol Oncol 95: 336-340, 2004.

11. Richter CE, Hui P, Buza N, Silasi DA, Azodi M, Santin AD, Schwartz PE and Rutherford TJ: HER-2/NEU overexpression in vulvar Paget disease: The Yale experience. J Clin Pathol 63: 544-547, 2010

12. Tanaka R, Sasajima Y, Tsuda H, Namikawa K, Tsutsumida A, Otsuka F and Yamazaki N: Human epidermal growth factor receptor 2 protein overexpression and gene amplification in extramammary Paget disease. Br J Dermatol 168: 1259-1266, 2013.

13. Wakabayashi S, Togawa Y, Yoneyama K, Suehiro K, Kambe N and Matsue H: Dramatic clinical response of relapsed metastatic extramammary Paget's disease to trastuzumab monotherapy. Case Rep Dermatol Med 2012: 401362, 2012.
14. Watanabe S, Takeda M, Takahama T, Iwasa T, Tsurutani J, Tanizaki J, Shimizu T, Sakai K, Wada Y, Isogai N, et al: Successful human epidermal growth receptor 2-targeted therapy beyond disease progression for extramammary Paget's disease. Invest New Drugs 34: 394-396, 2016.

15. Wolff AC, Hammond ME, Hicks DG, Dowsett M, McShane LM, Allison KH, Allred DC, Bartlett JM, Bilous M, Fitzgibbons $\mathrm{P}$, et al: Recommendations for human epidermal growth factor receptor 2 testing in breast cancer: American Society of Clinical Oncology/College of American Pathologists clinical practice guideline update. J Clin Oncol 31: 3997-4013, 2013.

16. Lien HC, Chen YL, Juang YL and Jeng YM: Frequent alterations of HER2 through mutation, amplification, or overexpression in pleomorphic lobular carcinoma of the breast. Breast Cancer Res Treat 150: 447-455, 2015.

17. Bose R, Kavuri SM, Searleman AC, Shen W, Shen D, Koboldt DC, Monsey J, Goel N, Aronson AB, Li S, et al: Activating HER2 mutations in HER2 gene amplification negative breast. Cancer Discov 3: 224-237, 2013.

18. Yoshino K, Fujisawa Y, Kiyohara Y, Kadono T, Murata Y, Uhara H, Hatta N, Uchi H, Matsushita S, Takenouchi T, et al: Usefulness of docetaxel as first-line chemotherapy for metastatic extramammary Paget's disease. J Dermatol 43: 633-637, 2016.

19. Sanli O, Dobruch J, Knowles MA, Burger M, Alemozaffar M, Nielsen ME and Lotan Y: Bladder cancer. Nat Rev Dis Primers 3: $17022,2017$.

20. Kirkali Z, Chan T, Manoharan M, Algaba F, Busch C, Cheng L, Kiemeney L, Kriegmair M, Montironi R, Murphy WM, et al: Bladder cancer: Epidemiology, staging and grading, and diagnosis. Urology 66 (6 Suppl 1): S4-S34, 2005.

21. Biserni GB, Engstrom MJ and Bofin AM: HER2 gene copy number and breast cancer-specific survival. Histopathology 69: 871-879, 2016

22. Fujiwara M, Suzuki T, Senoo A, Fukamizu H and Tokura Y: Evaluation of positron emission tomography imaging to detect lymph node metastases in patients with extramammary Paget's disease. J Dermato 44: 939-943, 2017.

23. Collarino A, Garganese G, Valdés Olmos RA, Stefanelli A, Perotti G, Mirk P, Fragomeni SM, Ieria FP, Scambia G, Giordano A and Rufini V: Evaluation of dual-timepoint ${ }^{18} \mathrm{~F}-\mathrm{FDG}$ PET/CT imaging for lymph node staging in vulvar cancer. J Nucl Med 58: 1913-1918, 2017.

24. Hatta N, Morita R, Yamada M, Echigo T, Hirano T, Takehara K, Ichiyanagi $\mathrm{K}$ and Yokoyama $\mathrm{K}$ : Sentinel lymph node biopsy in patients with extramammary Paget's disease. Dermatol Surg 30: 1329-1334, 2004.

25. Nakamura Y, Fujisawa Y, Ishikawa M, Nakamura Y, Ishitsuka Y, Maruyama H, Furuta J, Kawachi Y and Otsuka F: Usefulness of sentinel lymph node biopsy for extramammary Paget disease. $\mathrm{Br}$ J Dermatol 167: 954-956, 2012.

26. Chakrabarty A, Rexer BN, Wang SE, Cook RS, Engelman JA and Arteaga CL: H1047R phosphatidylinositol 3-kinase mutant enhances HER2-mediated transformation by heregulin production and activation of HER3. Oncogene 29: 5193-5203, 2010.

27. Xia W, Petricoin EF III, Zhao S, Liu L, Osada T, Cheng Q, Wulfkuhle JD, Gwin WR, Yang X, Gallagher RI, et al: An heregulin-EGFR-HER3 autocrine signaling axis can mediate acquired lapatinib resistance in HER2+ breast cancer models. Breast Cancer Res 15: R85, 2013.

28. Ebbing EA, Medema JP, Damhofer H, Meijer SL, Krishnadath KK, van Berge Henegouwen MI, Bijlsma MF and van Laarhoven HW: ADAM10-mediated release of heregulin confers resistance to trastuzumab by activating HER3. Oncotarget 7: 10243-10254, 2016.

29. Tanskanen M, Jahkola T, Asko-Seljavaara S, Jalkanen J and Isola J: HER 2 oncogene amplification in extramammary Paget's disease. Histopathology 42: 575-579, 2003.

30. Reich O, Liegl B, Tamussino K and Regauer S: p185HER 2 overexpression and HER2 oncogene amplification in recurrent vulvar Paget's disease. Mod Pathol 18: 354-357, 2005.

31. Ogawa T, Nagashima Y, Wada H, Akimoto K, Chiba Y, Nagatani T, Inayama Y, Yao M, Aoki I and Ikezawa Z: Extramammary Paget's disease: Analysis of growth signal pathway from the human epidermal growth factor receptor 2 protein. Hum Pathol 36: 1273-1280, 2005.

32. Plaza JA, Torres-Cabala C, Ivan D and Prieto VG: HER-2/neu expression in extramammary Paget disease: A clinicopathologic and immunohistochemistry study of 47 cases with and without underlying malignancy. J Cutan Pathol 36: 729-733, 2009. 
33. Miyamoto A, Akasaka K, Oikawa H, Akasaka T, Masuda T and Maesawa C: Immunohistochemical study of HER2 and TUBB3 proteins in extramammary Paget disease. Am $\mathrm{J}$ Dermatopathol 32: 578-585, 2010.

34. Kang Z, Zhang Q, Zhang Q, Li X, Hu T, Xu X, Wu Z, Zhang X, Wang $\mathrm{H}, \mathrm{Xu} \mathrm{J}$, et al: Clinical and pathological characteristics of extramammary Paget's disease: Report of 246 Chinese male patients. Int J Clin Exp Pathol 8: 13233-13240, 2015.

35. Tanaka R,Sasajima Y,Tsuda H, Tsuda H, Namikawa K, Takahashi A, Tsutsumida A, Fujisawa Y, Fujimoto M and Yamazaki N: Concordance of the HER2 protein and gene status between primary and corresponding lymph node metastatic sites of extramammary Paget disease. Clin Exp Metastasis 33: 687-697, 2016.

36. HikitaT,OhtsukiY,MaedaTandFurihataM:Immunohistochemical and fluorescence in situ hybridization studies on noninvasive and invasive extramammary Paget's disease. Int J Surg Pathol 20: 441-448, 2012

37. Karam A, Berek JS, Stenson A, Rao J and Dorigo O: HER-2/neu targeting for recurrent vulvar Paget's disease A case report and literature review. Gynecol Oncol 111: 568-571, 2008.

38. Takahagi S, Noda H, Kamegashira A, Madokoro N, Hori I, Shindo H, Mihara S and Hide M: Metastatic extramammary Paget's disease treated with paclitaxel and trastuzumab combination chemotherapy. J Dermatol 36: 457-461, 2009.
39. Hanawa F, Inozume T, Harada K, Kawamura T, Shibagaki N and Shimada S: A Case of metastatic extramammary Paget's disease responding to trastuzumab plus paclitaxel combination therapy. Case Rep Dermatol 3: 223-227, 2011.

40. Yoshimura N, Arihiro K, Takahagi S and Hide M: An autopsy case of metastatic extramammary Paget's disease treated with multimodality treatment including anti-HER2 therapy: What is the clinical and pathological significance of trastuzumab to the patient? Mod Chemother 02: 66-68, 2013.

41. Barth P, Dulaimi Al-Saleem E, Edwards KW, Millis SZ, Wong YN and Geynisman DM: Metastatic extramammary Paget's disease of scrotum responds completely to single agent trastuzumab in a hemodialysis patient: Case report, molecular profiling and brief review of the literature. Case Rep Oncol Med 2015: 895151, 2015.

42. Zhang X, Jin W, Zhu H and Yu H: Extramammary Paget's disease in two brothers. Indian J Dermatol 60: 423, 2015.

43. Shin DS, Sherry T, Kallen ME, Wong S and Drakaki A: Human epidermal growth factor receptor 2 (HER-2/neu)-directed therapy for rare metastatic epithelial tumors with HER-2 amplification. Case Rep Oncol 9: 298-304, 2016. International (CC BY-NC-ND 4.0) License. 